\title{
Interactive comment on "Synergistic effect of water-soluble species and relative humidity on morphological changes of aerosol particles in Beijing mega-city during severe pollution episodes" by Xiaole Pan et al.
}

\section{Anonymous Referee \#2}

Received and published: 17 September 2018

Comment on "Synergistic effect of water-soluble species and relative humidity on morphological changes of aerosol particles in Beijing mega-city during severe pollution episodes" by Xiaole Pan et al.

More and more attentions have been paid on air pollution (haze) due to their significant impacts on environment and climate. The article investigates the transformation of non-sphericity of mineral dust particles mixed with pollutants in Beijing based on the communities of study of atmospheric aerosol, especially dust and air pollutants. In 
general, I find this manuscript to be of interest for publication and appropriate for this journal. There are several suggestions for improvement listed below that should be considered by the authors before publication.

1. Until now there are lots of literatures introduced change of dust morphology during long-range transportation due to mixture with other substances over the past decades, not only based on on-line measurements (e.g., lidar remote sensing), but also in the laboratory analysis (e.g., SEM/TEM). In this paper, the authors should more clearly point out the key point of current study. It will be easier for readers to understand if the authors briefly summary some related studies in section Introduction.

2. Previous studies generally use volume depolarization ratio from lidar measurements to distinguish dust aerosols from others. Of course, POPC have its remarkable advantages. However, it should be noted that there is uncertainty when size of individual particles is estimated from POPC based on forward scattering signal at 60-degree, especially for non-spherical particles (like dust aerosols). So, the authors should discuss and/or introduce the uncertainty of particle size. And it is suggested that the authors should select two large interval sizes when discuss difference of DR at different size.

3. DR not only depend on shape of the particle, but also its size. In this study, authors discuss the difference of DR at different size, to prove change of dust morphology when they mix with other aerosols under high moisture condition. As shown in Fig. 4 , it seems there is an obvious peak of DR between 3-5 $\mu \mathrm{m}$ during the period of field campaign. So, in my opinion it should be careful to conclude.

4. Page 1 line 20: please delete "of" from "February of 2017".

5. Page 4 line 99: change "Februarys" to "February".

6. Page 6 line 87: change "in January29, 2017" to "on January 29, 2017".

Printer-friendly version

7. Page 17 line 85: add "(b)" at the end of the sentence.

Discussion paper

8. Aspect ratio is a key parameter for evaluating radiative effects of particles. The au- 
thors are encouraged to estimate this parameter from POPC observation in the future.

9. Page 6 line 87: change "in January29, 2017" to "on January 29, 2017".

10. Figure 6: it seems that backscattering coefficient is show in the upper panel according to the order of magnitude in colorbar. Please check carefully what is it. Besides, it is better to add volume depolarization ratio of aerosols from lidar measurements in the

Interactive figure, so that the readers will be easier to understand the results.

11. A paper about the effects of sulfuric acid and ammonium sulfate coatings on dust aerosols (Eastwood M. et al., 2009) was published in Geophys. Res. Lett.. Please reference this paper to increase reader understanding of interaction between dust and other aerosols. Furthermore, real-time transformation of dust aerosols morphology studied based on ground-based polarization-Raman lidar measurements (Huang Z. et al., 2018, Remote Sensing), will be very useful for readers to understand importance of depolarization ratio for aerosols investigation.

Please also note the supplement to this comment: https://www.atmos-chem-phys-discuss.net/acp-2018-623/acp-2018-623-RC1supplement.pdf

Interactive comment on Atmos. Chem. Phys. Discuss., https://doi.org/10.5194/acp-2018-623, 2018. 